\title{
COMPARING FAMILY ADAPTABILITY AND COHESION ACROSS UKRAINIAN-TURKISH AND TURKISH COUPLES: FEMALE PERSPECTIVE
}

\author{
Yulia KRYVENKO \\ Assistant Professor, Faculty of Health Sciences, Istanbul Sabahattin Zaim \\ University \\ E-mail: yulia.kryvenko@izu.edu.tr
}

\begin{abstract}
This study was performed to determine how a family function changes across intercultural and intracultural married couples. The subjects for the were 126 Ukrainian immigrant women and 158 Turkish women married to Turkish men living in Turkey. The family function of intercultural and intracultural families was measured using Family Adaptability and Cohesion Scale IV (FACES IV) developed by Goral and Olson in 2006. The mean family adaptability score for Turkish wives was 24.96 and 25.41 for Ukrainian wives, respectively. Families with Turkish wives scored higher on both balanced subscales (cohesion and flexibility) than families with Ukrainian wives, while families with Ukrainian wives scored slightly higher on all four unbalanced levels (enmeshed, disengaged, chaotic and rigid) than families with Turkish wives. Despite their nationality, those women who obtained higher education degrees, practiced the same religion as their husbands, and did not suffer from financial or familial pressure were found to be more balanced, and had better family communication, and overall higher family satisfaction.
\end{abstract}

Keywords: family adaptability, cohesion, flexibility, intercultural marriage. 


\section{Introduction}

Globalization and integration of cultures facilitate intercultural and interethnic interaction that leads to a growing number of intercultural families. In intercultural marriages, there are several problems that are not present in mono-ethnic marriages, such as spouses facing different cultures, values, and behaviours, problems associated with two different worlds. In such families, there may be disputes about the management of the household, the necessary degree of order in the house, ways of rearing the children and what language they should speak. On the other hand, the intercultural family is a microenvironment of inter-ethnic interactions and the exchange of ethnic values.

Comparing marital satisfaction across intercultural and intracultural marriages provides us with better understanding of the specifics of marital relationships and would allow for the provision of better psychological assistance to families and married couples, considering the specifics of their relationships and cultural affiliation.

"Marriage is the act, ceremony or process by which the legal relationship of husband and wife is constituted. The legality of the union may be established by civil, religious or other means as recognized by the laws of each country" (UN 2001:11). Antonov (2007) defines a family as a community of people connected by the ties of matrimony-parenthood-kinship and thus, carrying out the functions of reproduction, the succession of family generations, as well as the socialization of children and the maintenance of the existence of family members. The "nuclear" structure in this sociological version is represented in the trinity of matrimony - parenthood - kinship relations. The loss of one of these links characterizes the fragmentation of a family group. A complete picture of the family gives us relationships of the type: husband-wife; husband-children; wife-children; children-parents; children-children. These structural characteristics of the relatively independent family represent its socio-psychological unity. There may be different versions of a family, but a full-fledged family is one that has all types of relationships (Shneider, 2013)

Despite the close relationship between the concepts of "marriage" and "family", the family is a more complex system of relations than marriage, since it usually unites not only the spouses, but also their children, as well as other relatives or friends and the people fulfilling a need. According to the generally accepted definition, the family is a unit (small social group) of society, the most important form of organization of personal life, based on marital union and kinship ties, multilateral relations between husband and wife, parents and children, brothers and sisters and other relatives who live together and lead a common household. Family life is determined by the conditions of development of a particular society. These conditions determine the functions of the family and are generalized in legal and moral norms, and this, in turn, affects family positions, rules and roles in the family. 
The increase in the number of ethnically mixed marriages and, consequently, interethnic families in modern society is one of the results the changes that have taken place are not just in individual countries, but also in the world as a whole (Zelenskaya, 2016). One of the manifestations of the social change is the emergence of more complex forms of families and relationships. Not only social, but also the ethnic composition of the population has become more complex. Modern countries are usually multi-ethnic, consisting of people who belong to different nationalities and different faiths. Modern society is also characterized by rapid development of migration processes that affect the ethnic structure of the population and interethnic marriage. For example, the collapse of the Soviet Union became a catalyst for the migration inside the post-Soviet space and outside its borders. An additional change in the world can be seen in the development of an international labour market. Developed countries are characterized by a reduction in the share of their own working-age population. This encourages local authorities to fill the labour deficit with migrants. The presence of open borders, the desire to find more highly paid jobs encourage people to migrate. In the host countries, migrants have become a profitable labour force. The creation of international families is also facilitated by the Internet, where many sites offer acquaintance with foreigners for several purposes including the purpose of creating a family. Intercultural marriages are defined in this study as marriages between two culturally different individuals who have separate national cultures that influence their individual worldviews, beliefs, and personal ideologies. For this study, culture is defined as "inclusive of common ethnic, linguistic, racial, and historical backgrounds" (Kim, 2008)

It is difficult to identify the exact number of intercultural marriages worldwide. However, statistics suggest that it is rapidly increasing because of globalization. (Smith, Maas, \& van Tubergen, 2012). Since 2009, Turkish marriage statistics for intercultural marriages have been available, and various motivations for marriage have been described, including obtaining permanent residence and work authorization (USAK report, 2008). According to the Turkish Statistical Institute (Turkey in Statistics, 2009), 2.9 percent of all marriages were intercultural, rising to $3.11 \%$ (TURKSTAT, Marriage Statistics, 2011) in two years, with German-Turkish marriages accounting for the highest percentage of these at 21.4 percent. The number of foreign brides in 2020 was 18,909 or $3.9 \%$ of the total brides. When foreign brides were examined by nationality, Syrian brides ranked first among foreign brides with $14.8 \%$, followed by Azerbaijani brides with $10.5 \%$ and German brides with 9.4\%. Ukrainian brides amounted to $5.5 \%$ and ranked $7^{\text {th }}$ among the total amount of foreign brides (TURKSTAT, Marriage Statistics, 2020). According to the Ukrainian Embassy in Turkey, there are about 35 thousand Ukrainians who permanently or temporarily live in Turkey, concentrated mostly in Istanbul and Antalya, the two largest touristic cities in Turkey (Ukranians in Turkey, 2012). Ukraine and Turkey have a long chronology of historical, geographic, and cultural contact. Despite some explicit cultural differences such as food, language and religion, these two countries have a lot in common. When 
analysed, for example, through the lens of the Hofstede model of national culture (Hofstede et al, 2010), Turkey and Ukraine showed significantly different scores only on the dimension of long-term orientation versus short term normative orientation (LTO), with Ukraine being scored as "a very pragmatic culture", while Turkey emerged to be a normative society that tends toward the maintenance of time-honoured traditions (Country Comparison, 2021). As for the remaining dimensions, both countries demonstrated high power distance (PDI) and uncertainty avoidance (UAI) scores, while individualism (IDV), masculinity (MAS) and indulgence (IVR) scores were relatively low.

Although there has been substantial research on conflict management and effective communication across intercultural marriages (e.g., TingToomey et al., 2001) few studies have closely examined intercultural marital satisfaction. Within the United States studies of intercultural coupling have considered such issues as interracial (e.g., McNamara, Tempenis, \& Walton, 1999; Spickard, 1989; Root, 2001), and interfaith marriages (e.g., Crohn, 1995; Ho, 1984). Within the Europe, studies have involved the general trends for mixed marriages (Lanzieri, 2012), considerations of divorce among spouses in intercultural marriages (Lainiala\& Säävälä, 2013). Within Asia sociodemographic characteristics of intercultural marriage (Jo-Pei, Baharuddin, Juhari \& Krauss, 2008), Asian marriage migrants' experience of integration and assimilation (Wei-Jun \& Zheng, 2019) has been studied. However, the study of marital satisfaction between Ukrainian-Turkish and Turkish married couples has not received sufficient attention. Considering the substantial differences between Turks and Ukrainians that were mentioned above, a better understanding of the nature of marital adaptation will help advance intercultural and interpersonal relations.

\section{Method}

\section{Participants}

Most of the Ukrainian women live in two Turkish cities, Istanbul and Antalya ("Ukranians in Turkey", 2020). In this study there was a total of 279 female participants. The sample was predominantly upper middle class. The ages ranged from $18-70$ for both Ukrainian and Turkish women. The first group had 126 (44\%) Ukrainian females and the second group consisted of 158 $(56 \%)$ Turkish females. Among them 22 (8\%) women were 18-25 years old, $111(39 \%)$ were 26-36 years old, 96 (34\%) were 37-45, 48 (17\%) women were 46-56, and only 6 participants were 57-70 (2.2\%). The educational level ranged from elementary school to university: 136 (48\%) women did not have higher education. The religion of Ukrainians varied, by the time of the interviews 14 women had become Muslim. As for the Turkish females, all of them were Muslims. In total there was 172 (61\%) Muslims participating in the interviews, 96 (34\%) Christians, other religions made up 5\% respectively. Among 
Ukrainian participants 30\% lived in Turkey before marriage. Out of 279 participants only 101 (36\%) were officially employed.

As requirement for participation all the subjects were all married to Turkish males, they have been married for at least 4 years and have been residing in Turkey since the beginning of their marriage.

A structured survey of these subjects was performed during 2019. Two graduate students majoring in social work helped to conduct the interview with Turkish women, and the researcher herself interviewed the Ukrainian women.

\section{Measures}

Family Adaptability and Cohesion Evaluation Scale-IV Family functioning was measured using the Family Adaptability and Cohesion Evaluation Scale IV (FACES-IV; Olson, 2011). The FACES-IV is composed of two Balanced Scales: seven questions that attribute to Balanced Cohesion (e.g., Family members are involved in each other's lives), and seven questions that attribute to Balanced Flexibility (e.g., Our family tries new ways of dealing with problems). There are four Unbalanced Scales with seven questions each: Disengaged (e.g., We get along better with people outside our family than inside), Enmeshed (e.g. We spend too much time together), Rigid (e.g., There are strict consequences for breaking the rules in our family), and Chaotic (e.g., We never seem to get organized in our family). The measurement produces a circular ratio by dividing the balanced subscales into extreme subscales: Cohesion Ratio $=[$ Balanced Cohesion $] /[($ Disengaged + Enmeshed $) / 2] ;$ Flexibility Ratio $=[$ Balanced Flexibility $] /[($ Rigid + Chaotic $) / 2] ;$ Circumplex Total Ratio $=$ [(Cohesion Ratio + Flexibility Ratio $) / 2]$. The higher level of circumplex total ratio refers to a more balanced family system according to this formulation (Olson, 2011). Interpretation of the FACES-IV yields a Circumplex total ratio figure, which indicates a family's balanced and unbalanced characteristics in a single score. One of the advantages of the Balanced/Unbalanced ratio score is that it provides a methodological approach for assessing the curvilinearity of cohesion and flexibility. The higher the ratio score above 1, the more balanced the system. Conversely the lower the ratio score below 1, the more unbalanced the system (Olson \& Gorall, 2006).

The FACES-IV has demonstrated good internal consistency $(\alpha=.77$ .89) across all scales (Olson, 2011), although the enmeshment scale demonstrated less than acceptable internal reliability $(\alpha=.65)$ in one study (Marsac \& Alderfer, 2011). Construct validity of the FACES-IV has been supported by strong correlations $(r=.89-.99)$ with other measures of family functioning except for the enmeshed and rigid scales, which displayed only small correlations (Olson, 2011). Construct validity has also been demonstrated in the results of confirmatory factor analyses which supported the six-subscale model of the FACES-IV (Olson, 2011). In this study, the FACES demonstrated acceptable to good reliability for the Flexibility $(\alpha=.72)$, Disengaged $(\alpha=.69)$, Enmeshed $(\alpha=.64)$, Rigid $(\alpha=.72)$, Family Communication $(\alpha=.90)$, Family Satisfaction $(\alpha=.90)$ subscales. However, the Cohesion subscale demonstrated poor reliability $(\alpha=.54)$ in this study, while the Chaotic subscale also demonstrated suboptimal reliability $(\alpha=.57)$. The quality of the 
communication skills between family members is measured with Family Communication Scale (e.g., Family members are satisfied with how they communicate with each other), and the quality of functioning of the family system is measured with the family satisfaction scale (e.g., How satisfied are you with the degree of closeness between family members?). Each of these two scales consists of ten items, with the items also being evaluated with 5-point Likert scale. Cronbach-alpha coefficient was .90 for the family communication scale, and .92 for the family satisfaction scale (Olson et al., 2007). The high scores on these scales, reveal the quality of the communication and satisfaction in family system.

Family Adaptability and Cohesion Scale IV Questionnaire Package was validated with different ethnic groups including Russian and Turkish. FACES IV was translated and adapted to Turkish by Türkdoğan, Duru and Balkis (2018). Cronbach-alpha coefficients ranged between .65 and .91, the average variance extracted coefficients ranged between .33 and .57 , and the composite reliability coefficients ranged be-tween .66 and .90 for the FACES IV sub-scales (Turkdogan, Duru, \& Balkis, 2018). Russian adaptation of FACES IV that was used in this study was done by Zelenskaya in 2016. The Cronbach-alpha coefficient was .86 for the Balanced Cohesion subscale, .78 for the Disengaged, and .77 for the Enmeshed, . 78 for the Balanced Flexibility, .60 for the Rigid subscale, .62 for the Chaotic, .90 for the Communication, and .93 for the Satisfaction subscale in the Russian adaptation of the scale (Zelenskaya, 2016).

\section{Statistical Techniques Used in Data Analysis}

Normality test of all subscale scores was performed before carrying out statistical processes on Family Adaptability and Cohesion Evaluation Subscales. Accordingly, Skewness and Kurtosis values for all scale scores range between -0.125 and 1.225. According to Tabachnick and Fidell (2013), if Skewness and Kurtosis values are between -1.50 and +1.50 , scores obtained from the test exhibit normality. Thus, parametric tests were utilized in the analysis of scores obtained from the test. In this context, non-relational t-test was used to test the significance of difference between means of the two groups and one-way variance analysis (ANOVA) to test the significance of difference between means of more than two groups. Furthermore, arithmetic means and standard deviation values were calculated for descriptive statistics of subscale scores. 


\section{Findings}

Table 1. T-Test Results for Families' Family Adaptability and Cohesion Evaluation Subscale Scores by Whether the Wife is Ukrainian or Turkish

\begin{tabular}{|c|c|c|c|c|c|c|c|}
\hline Subscales & $\begin{array}{l}\text { Wife's } \\
\text { nationality }\end{array}$ & $\mathrm{N}$ & Mean & $\begin{array}{l}\text { Standard } \\
\text { Deviation }\end{array}$ & sd & $\mathrm{t}$ & $\mathrm{P}$ \\
\hline \multirow{2}{*}{$\begin{array}{l}\text { Balanced } \\
\text { Cohesion }\end{array}$} & Ukrainian & 123 & 28.8537 & 4.34323 & \multirow[t]{2}{*}{271} & \multirow[t]{2}{*}{2.89} & \multirow[t]{2}{*}{.042} \\
\hline & Turkish & 150 & 30.1400 & 6.41834 & & & \\
\hline \multirow{2}{*}{$\begin{array}{l}\text { Balanced } \\
\text { Flexibility }\end{array}$} & Ukrainian & 123 & 24.9024 & 3.61784 & \multirow[t]{2}{*}{271} & \multirow[t]{2}{*}{3.63} & \multirow[t]{2}{*}{.000} \\
\hline & Turkish & 150 & 27.0800 & 5.77953 & & & \\
\hline \multirow[t]{2}{*}{ Disengaged } & Ukrainian & 121 & 15.6529 & 4.14872 & \multirow[t]{2}{*}{263} & \multirow[t]{2}{*}{1.71} & \multirow[t]{2}{*}{.087} \\
\hline & Turkish & 144 & 14.5903 & 5.64251 & & & \\
\hline \multirow[t]{2}{*}{ Enmeshed } & Ukrainian & 122 & 20.2951 & 3.81318 & \multirow[t]{2}{*}{265} & \multirow[t]{2}{*}{6.15} & \multirow[t]{2}{*}{.000} \\
\hline & Turkish & 145 & 16.7862 & 5.24164 & & & \\
\hline \multirow[t]{2}{*}{ Rigid } & Ukrainian & 120 & 19.5917 & 3.92042 & \multirow[t]{2}{*}{263} & \multirow[t]{2}{*}{7.42} & \multirow[t]{2}{*}{.000} \\
\hline & Turkish & 145 & 15.2690 & 5.28790 & & & \\
\hline \multirow[t]{2}{*}{ Chaotic } & Ukrainian & 122 & 15.5164 & 3.58425 & \multirow[t]{2}{*}{267} & \multirow[t]{2}{*}{1.39} & \multirow[t]{2}{*}{.163} \\
\hline & Turkish & 147 & 14.7415 & 5.17911 & & & \\
\hline \multirow{2}{*}{$\begin{array}{l}\text { Family } \\
\text { Communication }\end{array}$} & Ukrainian & 122 & 39.8443 & 7.05119 & \multirow[t]{2}{*}{265} & \multirow[t]{2}{*}{.084} & \multirow[t]{2}{*}{.933} \\
\hline & Turkish & 145 & 39.7655 & 8.01042 & & & \\
\hline \multirow{2}{*}{$\begin{array}{l}\text { Family } \\
\text { Satisfaction }\end{array}$} & Ukrainian & 119 & 38.7227 & 7.63236 & \multirow[t]{2}{*}{270} & \multirow[t]{2}{*}{.537} & \multirow[t]{2}{*}{.592} \\
\hline & Turkish & 153 & 38.2026 & & & & \\
\hline
\end{tabular}

As seen in Table 1, among Family Adaptability and Coherence Evaluation subscales, Balanced Cohesion subscale scores differed significantly between groups depending on whether the wife is Ukrainian or Turkish. Families with Turkish wives had higher Balanced Cohesion and Balanced Flexibility scores than families with Ukrainian wives. While families with Ukrainian wives had higher Enmeshed and Rigid scores than families with Turkish wives.

No significant differences were observed in scores from other Family Adaptability and Coherence Evaluation subscales depending on whether the wife is Ukrainian or Turkish. 
Table 2. ANOVA Results for Families' Family Adaptability and Coherence Evaluation Subscale Scores by Level of Graduation

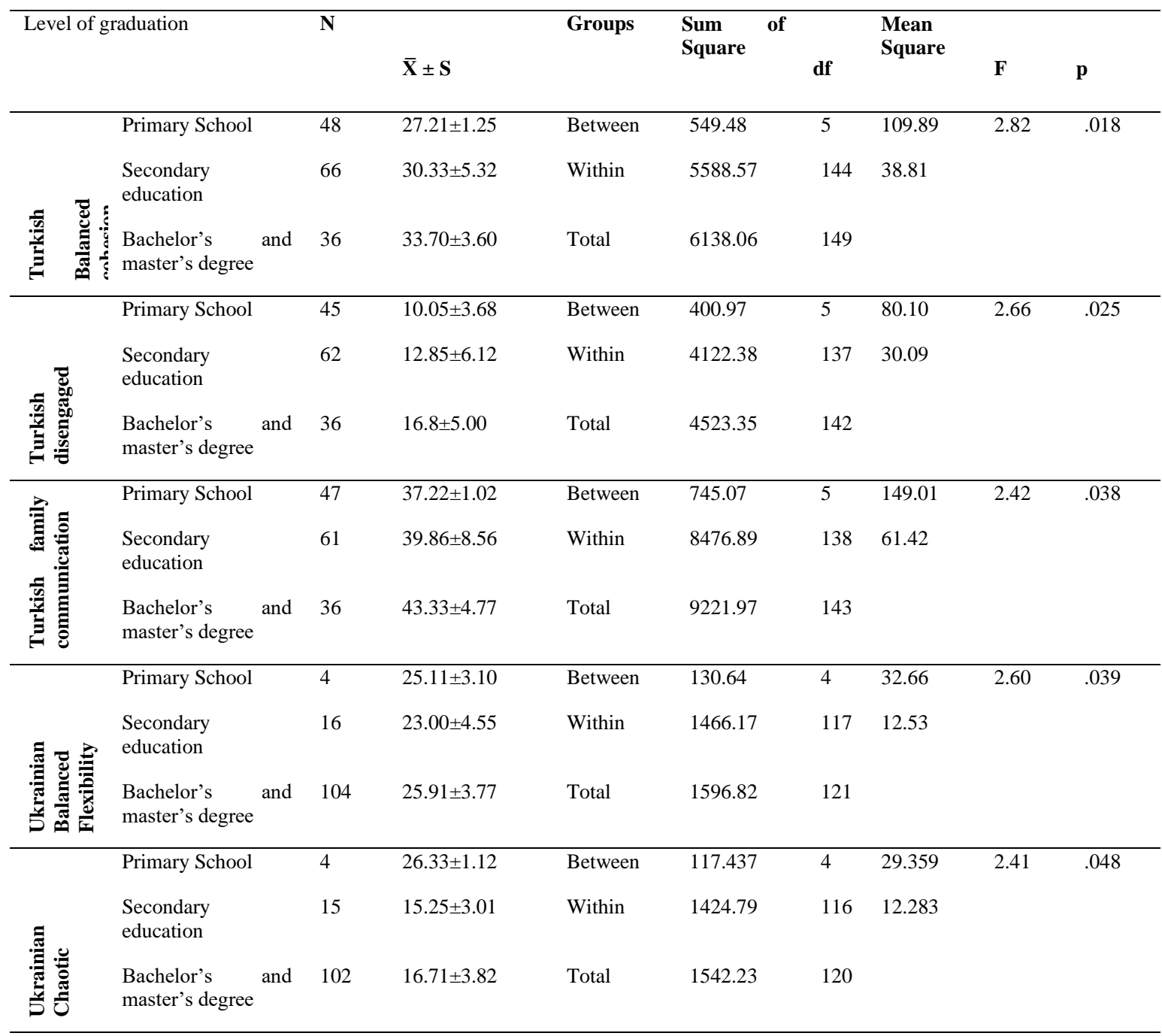

According to the analysis results, among Family Adaptability and Coherence Evaluation subscales, Balanced Cohesion subscale scores differed significantly by "level of graduation" in families with Turkish wives. The Scheffe test was used to make multiple comparisons between unequal group variances (Scheffe, 1959). Whether there was a significant difference between the groups was tested with the Scheffe test, and it was observed that Balanced Cohesion scores were higher in families with wives who have a bachelor's and master's degree. 
Among Family Adaptability and Coherence Evaluation subscales, Disengaged and Family Communication subscale scores were higher in families with wives who have a bachelor's and master's degree.

Among Family Adaptability and Coherence Evaluation subscales, Balanced Flexibility subscale scores differed significantly by "level of graduation" in families with Ukrainian wives. It was observed that Balanced Flexibility scores were higher in families with wives who are graduates of secondary education. While Chaotic scores were higher in families with wives who are graduates of only primary school.

Table 3. ANOVA Results for Families' Family Adaptability and Coherence Evaluation Subscale Scores by Religion

\begin{tabular}{|c|c|c|c|c|c|c|c|c|c|}
\hline \multicolumn{2}{|c|}{ Religion } & $\mathbf{N}$ & $\overline{\mathbf{X}} \pm \mathrm{S}$ & Groups & $\begin{array}{l}\text { Sum of } \\
\text { Square }\end{array}$ & \multicolumn{2}{|r|}{$\begin{array}{l}\text { Mean } \\
\text { Square }\end{array}$} & $\mathbf{F}$ & $\mathbf{P}$ \\
\hline \multirow{3}{*}{ 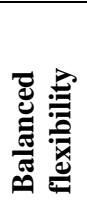 } & Muslim & 163 & $26.22 \pm 5.88$ & Between & 261.89 & 3 & 87.29 & 3.50 & .016 \\
\hline & Christian & 95 & $24.11 \pm 3.12$ & Within & 6623.20 & 266 & 24.89 & & \\
\hline & Other & 12 & $25.45 \pm 2.11$ & Total & 6885.09 & 269 & & & \\
\hline \multirow{3}{*}{ 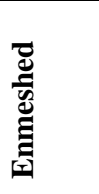 } & Muslim & 163 & $17.22 \pm 5.33$ & Between & 549.44 & 3 & 183.14 & 7.90 & .000 \\
\hline & Christian & 95 & $20.95 \pm 3.41$ & Within & 6023.59 & 260 & 23.16 & & \\
\hline & Other & 12 & $20.65 \pm 4.10$ & Total & 6573.03 & 263 & & & \\
\hline \multirow[b]{3}{*}{ 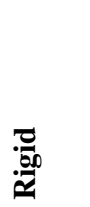 } & Muslim & 163 & $15.22 \pm 5.21$ & Between & 844.92 & 3 & 281.64 & 11.75 & .000 \\
\hline & Christian & 95 & $19.52 \pm 3.85$ & Within & 6207.92 & 259 & 23.96 & & \\
\hline & Other & 12 & $17.52 \pm 4.73$ & Total & 7052.85 & 262 & & & \\
\hline
\end{tabular}

According to the analysis results, among Family Adaptability and Coherence Evaluation subscales, Balanced Flexibility subscale scores differed significantly by "religion". It was observed that families with Muslim wives had higher Balanced Flexibility scores than families with Christian wives.

Among Family Adaptability and Coherence Evaluation subscales, Enmeshed subscale scores differed significantly by "religion". It was observed that families with Christian wives had higher Enmeshed and Rigid scores than families with Muslim wives.

No significant differences were observed in scores from other Family Adaptability and Coherence Evaluation subscales by religion. 
Table 4. ANOVA results for Family Adaptability and Coherence Evaluation Subscales by How Families Go to Visit Relatives

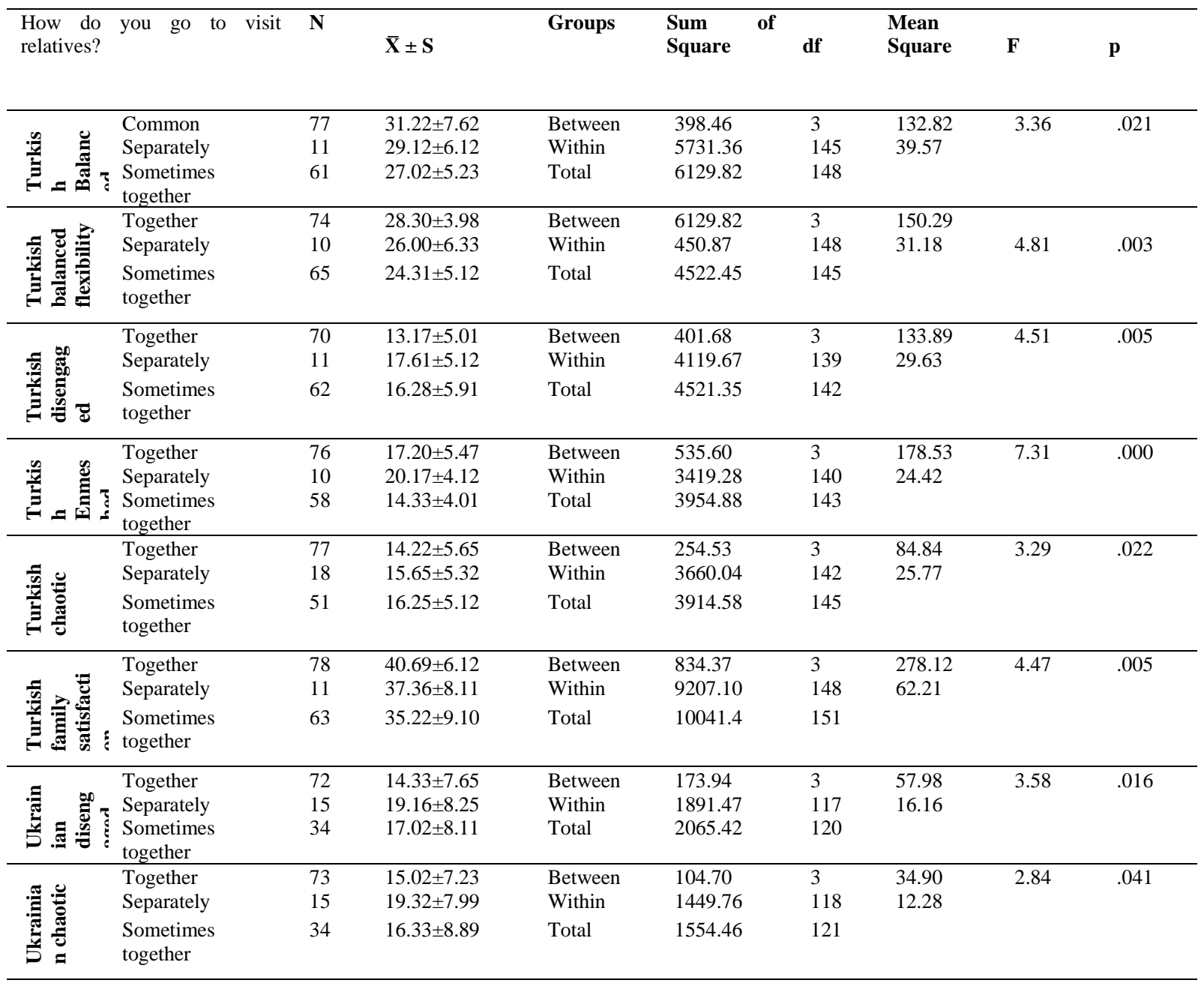

According to the analysis of the results, among Family Adaptability and Coherence Evaluation subscales, Balanced Cohesion subscale scores differed significantly by "how families with Turkish wives go to visit their relatives". It was observed that Balanced Cohesion, Balanced Flexibility and Family Satisfaction scores were higher in families who go to visit relatives together rather than separately.

Among Family Adaptability and Coherence Evaluation subscales, Disengaged subscale scores differed significantly by "how families with Turkish wives go to visit their relatives". It was observed that families who go to visit relatives separately and sometimes together had higher Disengaged, Enmeshed and Chaotic scores than families who go to visit relatives together. 
Among Family Adaptability and Coherence Evaluation subscales, Disengaged subscale scores differed significantly by "how families with Ukrainian wives go to visit their relatives" [ $\mathrm{f}(3-117)=3.58, \mathrm{p}<.05]$. It was observed that families who go to visit relatives separately had higher Disengaged scores and Chaotic scores than families who go to visit relatives together all the time.

No significant differences were observed in scores from other Family Adaptability and Coherence Evaluation subscales by how families go to visit relatives.

\begin{tabular}{|c|c|c|c|c|c|c|c|c|c|c|}
\hline $\begin{array}{l}\text { Duration } \\
\text { Each } \\
\text { Marriage }\end{array}$ & $\begin{array}{l}\text { of } \mathrm{Kn} \\
\text { Other }\end{array}$ & $\begin{array}{l}\text { wing } \\
\text { efore }\end{array}$ & $\mathbf{N}$ & $\bar{X} \pm S$ & Groups & $\begin{array}{l}\text { Sum of } \\
\text { Square }\end{array}$ & df & $\begin{array}{l}\text { Mean } \\
\text { Square }\end{array}$ & $\mathbf{F}$ & $\mathbf{P}$ \\
\hline \multirow{3}{*}{ ס } & 1 year & & 83 & $26.56 \pm 6.78$ & Between & 320.16 & 4 & 80.04 & 2.58 & .039 \\
\hline & 2 year & & 16 & $27.35 \pm 5.12$ & Within & 4457.29 & 144 & 30.95 & & \\
\hline & $\begin{array}{l}3 \text { year } \\
\text { longer }\end{array}$ & and & 50 & $29.85 \pm 3.57$ & Total & 4777.46 & 148 & & & \\
\hline \multirow{3}{*}{ 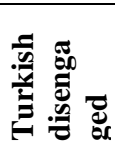 } & 1 year & & 80 & $15.32 \pm 5.12$ & Between & 650.76 & 4 & 162.69 & 5.72 & .000 \\
\hline & 2 year & & 17 & $16.48 \pm 6.45$ & Within & 3896.21 & 138 & 28.23 & & \\
\hline & $\begin{array}{l}3 \text { year } \\
\text { longer }\end{array}$ & and & 46 & $11.02 \pm 4.12$ & Total & 4546.97 & 142 & & & \\
\hline \multirow{3}{*}{ 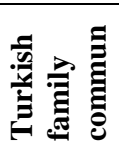 } & 1 year & & 81 & $37.01 \pm 9.45$ & Between & 602.58 & 4 & 150.64 & 2.46 & .049 \\
\hline & 2 year & & 18 & $39.45 \pm 7.36$ & Within & 8560.07 & 139 & 61.58 & & \\
\hline & $\begin{array}{l}3 \text { year } \\
\text { longer }\end{array}$ & and & 45 & $42.24 \pm 6.14$ & Total & 9162.66 & 143 & & & \\
\hline \multirow{3}{*}{ 昰 } & 1 year & & 85 & $36.32 \pm 7.65$ & Between & 721.98 & 4 & 180.49 & 2.58 & .026 \\
\hline & 2 year & & 18 & $36.68 \pm 8.10$ & Within & 9346.73 & 148 & 63.15 & & \\
\hline & $\begin{array}{l}3 \text { year } \\
\text { longer }\end{array}$ & and & 50 & $41.38 \pm 6.10$ & Total & 10068.7 & 152 & & & \\
\hline \multirow{3}{*}{ 醇 } & 1 year & & 62 & $15.00 \pm 7.35$ & Between & 148.50 & 4 & 37.12 & 3.09 & .019 \\
\hline & 2 year & & 20 & $15.20 \pm 6.12$ & Within & 1405.95 & 117 & 12.01 & & \\
\hline & $\begin{array}{l}3 \text { year } \\
\text { longer }\end{array}$ & and & 40 & $14.10 \pm 5.45$ & Total & 1554.46 & 121 & & & \\
\hline
\end{tabular}

\section{Table 5. ANOVA Results for Families' Family Adaptability and Coherence Evaluation Subscale Scores by Duration of Knowing Each Other before Marriage}

According to the analysis results, among Family Adaptability and Coherence Evaluation subscales, Balanced Flexibility subscale scores differed significantly by "duration of knowing each other before marriage" in families with Turkish wives. It was observed that families with couples having known each other for 3 years or longer had higher Balanced Flexibility, Family Communication and Family Satisfaction scores.

Among Family Adaptability and Coherence Evaluation subscales, Disengaged subscale scores differed significantly by "duration of knowing each 
other before marriage" in families with Turkish wives. It was observed that Disengaged scores were higher in families with couples having known each other for 2 years than in families with couples having known each other for 3 years and longer.

Among Family Adaptability and Coherence Evaluation subscales, disengaged subscale scores differed significantly by "duration of knowing each other before marriage" in families with Ukrainian wives. It was observed that among couples who had known each other for one year, Chaotic scores were higher than among couples who had known each other for two and more years before marriage.

No significant differences were observed in scores from other Family Adaptability and Coherence Evaluation subscales by duration of knowing each other before marriage.

\section{Discussion}

This study was conducted to examine and compare the level of family adaptability and satisfaction in intercultural and intracultural married couples. Adaptability, according to Olson (1986), refers to a family's ability to come up with new solutions to challenges, compromise, and change roles and obligations when faced with situational or developmental stress. Adaptability has also been linked to marital satisfaction (Olson, 2011). In this study, the average family adaptability score for Turkish wives was 24.96 and 25.41 for Ukrainian wives, respectively. This research showed similar results to those in the study by Olson of middle-class families in the USA which indicated a mean family adaptability score of 24.1, and in the study by Lim et al. which reported a mean family adaptability score of 24.9 in Korean families (Olson, 1986; Lim et al., 1989).

The overall results of this study indicate that there is a slight difference in the family adaptation in favour of intracultural marriages. Families with Turkish wives scored higher on both balanced subscales (cohesion and flexibility) than families with Ukrainian wives, while families with Ukrainian wives scored slightly higher on all four unbalanced levels (enmeshed, disengaged, chaotic and rigid) than families with Turkish wives. However, the general evaluation shows that a high percentage of this sample found it easy to adapt, and that they were comfortable living in Turkey. This result is confirmed by the circumplex total ratio with Turkish women's ratio score of 1.86 and Ukrainian participants' of 1.62. Since in both cases it was higher than 1 , the systems are considered balanced. There are several possible reasons why there was a difference between the Ukrainians and Turks adaptability level. One reason is Turkish and Ukrainian cultures both have high power distance (PDI) and low individualism (IDV) scores. According to Oetzel et al. (2007) these two dimensions are the ones that receive the most credit for understanding 
intercultural conflict. It is argued that conflict styles can be handled and built in such a manner that culture is integrated into the interpretation and comprehension of these styles. Another reason is Ukrainian women who were selected for the interviews have been living in Turkey for a long time, therefore they have had a chance to adapt to the customs and traditions of the host country. A third reason, for a high level of adaptation, may be because they are more flexible individuals when compared to the Ukrainians residing in Ukraine. A fourth arguable reason is that they have found their own pattern of adjustment which helped them to adapt (Preto, McGoldrick, 2005).

The duration of spouses knowing each other before marriage proved to be an influencing factor for Balanced Flexibility, Family Communication and Family Satisfaction in Turkish marriages. Those who knew each other for three and more years scored higher. It supports the results of Francis-Tan \& Mialon (2015) study in which dating three or more years decreased the likelihood of a divorce to about $50 \%$ lower at any given point in time. This suggests that it can be helpful to date at least a few years prior to entering a marriage (DiDonato, 2017).

Regardless of nationality, there was a significant difference between the families who go to visit relatives together. It was observed that these families had higher Balanced Cohesion and Balanced Flexibility scores. According to Olson (1999, p. 151) "balanced types of couples and families on cohesion allow their members to experience being both independent from and connected to their family. On flexibility, balance means maintaining some level of stability in a system with openness to some change when it is necessary".

Also, regardless the wives' culture, it was found that Balanced Cohesion, Family Communication, Balanced Flexibility scores were higher in families with wives who had higher education while Chaotic scores were higher in families with wives who are graduates of only primary school. According to Boertien and Härkönen (2018) one of the reasons why educated women's marriages would have higher marital satisfaction is that their families have fewer economic stressors and less economic insecurity. Moreover, research shows that educated women are able to bargain for a more even distribution of childcare and housework (Bonke and Esping-Andersen 2011), which improves marital satisfaction and marital stability (e.g., Cooke 2006; Oláh and Gähler 2014).

Families with wives who had higher education, same religion with their husbands (Islam in this case) and did not suffer from financial or familial pressure were found to be more balanced, had better family communication and overall higher family satisfaction. The findings of this study were close to those of Friedman et al. and Ahn, who used the FACES III to examine how family income, educational background, and religion influenced family adaptability (Friedman et al., 1987; Ahn, 1988). However, since most previous studies were 
cross-sectional and used different sample group, it is difficult to compare them directly. Future research is needed.

There were no significant differences observed in Family Communication, Family Satisfaction, Enmeshed and Disengaged scores depending on whether the wife is Ukrainian or Turkish. This finding suggests a cultural change in Turkey which is changing family functioning, to where there are few set rules and customs. Preliminary work in this shows that upper middle socio-economic class status Turkish families seem to report that they are more unstructured, changeable, and flexible with their rules and roles in the family (Sunar\&Fisek, 2005). These studies also show that there appears to be a difference between upper and lower socioeconomic status Turkish families in this respect. The lower socioeconomic status families seem to be more structured and stricter with their rules and roles.

In addition, there was no significant differences found in scores from Family Adaptability and Coherence Evaluation subscales by duration of knowing each other before marriage, or how often families go to visit their relatives. Apart from the reasons mentioned above, the low subject number had an influence on the research findings. Since there was a low number of subjects it was impossible to group subjects according to such important characteristics as age or their length of stay in Turkey. A larger sample would have provided more information, especially if there were equal groups of subjects who have been living in Turkey for different length of time. In the future, a large-scale population study might be required.

Another recommendation for further research could be to compare different cultures, such as Russian or Syrian wives living in Turkey. Since Syrian culture is more familiar with the Turkish culture and may be closer to it in more respects than Ukrainian culture.

\section{Conclusion}

The results obtained from this study may have several meaningful interpretations. It was found that levels of family adaptability in intercultural and intracultural marriages are similar, with Ukrainian wives showing almost identical levels of adaptation and satisfaction with their family life. This means that once Ukrainian women settle down and live in Turkey for a while, they adapt to the lifestyle, their functioning becomes similar to the Turkish families even though they are different in the content of the issues involved. The findings also suggest a cultural shift in Turkey, which is leading to a change in family functioning toward one with less fixed laws and customs. Such factors as ethnicity, religion or relationships with family relatives are playing less of a role. 


\section{Bibliography}

Ahn Y.H. (1988) Analysis of the Relationship between Family Adaptability and Family Cohesion and Male Adolescent' Mental Health. Yonsei University, Seoul. (In Korean.)

Antonov, A. (2007). Sociology of Family. Moscow, Russia: INFA-M.

Boertien, D., \& Härkönen, J. (2018). Why does women's education stabilize marriages? The role of marital attraction and barriers to divorce. Demographic

Research, 38, 1241- 1276. https://doi.org/10.4054/DemRes.2018.38.4 1 .

Bonke, J. and Esping-Andersen, G. (2011). Family investments in children: Productivities, preferences, and parental childcare. European Sociological Review 27(1), 43-55. doi:10.1093/esr/jcp054.

Cooke, L.P. (2006). Doing gender in context: Household bargaining and risk of divorce in Germany and the United States. American Journal of Sociology 112(2), 442-472. DOI:10.1086/506417.

Country Comparison (2021). Hofstede Insights. https://www.hofstedeinsights.com/country-comparison/turkey,ukraine/, Accessed November 2021.

Crohn, J. (1995). Mixed matches: how to create successful interracial, interethnic, and interfaith relationships. NY: Fawcett Columbine.

Didonato, T. E. (2017). How long should you date before getting married? Retrieved from

https://www.psychologytoday.com/us/blog/meet-catch-and-keep/, Accessed November 2021.

Francis, A. M., \& Mialon, H. M. (2014). 'A Diamond is Forever' and other fairy tales: The relationship between wedding expenses and marriage duration. Retrieved on March 23, 2015, from Social Science Research Network: http://dx.doi.org/10.2139/ssrn.2501480.

Friedman, A. S., Utada, A., \& Morrissey, M. R. (1987). Families of adolescent drug abusers are "rigid": Are these families either "disengaged" or "enmeshed," or both? Family Process, 26(1), 131148. https://doi.org/10.1111/j.1545-5300.1987.00131.x.

Gorall, T. M., Tiesel, J., \& Olson, D. H. (2006). FACES IV: Development and validation. Minneapolis, MN: Life Innovations.

Hofstede, G., Hofstede, G. J., \& Minkov, M. (2010). Cultures and Organizations: Software of the mind. New York: McGraw-Hill.

Kim, Y.Y. (2008). Intercultural personhood: Globalization and a way of being, International Journal of Intercultural Relations, 32(4), 359-368.

Lanzieri, G. (2012). Mixed marriages in Europe 1990-2010. In: Doo-Sub, K. (ed.). Cross-border marriage: Global trends and diversity. Seoul: Korea Institute for Health and Social Affairs: 81-122.

Lainiala, L. and Säävälä, M. (2013). "Intercultural marriages and consideration of divorce in Finland: Do value differences matter?" The Population Research Institute. Available at http://vaestoliittofibin.directo.fi/@Bin/2ca9a1885ac8ac37a31f19d6d7905d58/1476104 
113 054/application/pdf/2861591/WP4Lainiala\%26Saavala.pdf, Accessed October 2020.

Marsac, M., \& Alderfer, M. (2011). Psychometric properties of the FACES-IV in a pediatric oncology population. Journal of Pediatric Psychology, 36(5), 528-538.

McGoldrick, M., \& Preto, N. G. (1984). “Ethnic intermarriage: Implications for therapy". Family Process, 23(3), 347364. https://doi.org/10.1111/j.1545-5300.1984.00347.x.

McNamara, P.R., Tempenis, M., \& Walton, B. (1999). Crossing the line: Interracial couples in the South. Connecticut: Greenwood.

Oetzel, J., Getz, K. A., Ladek, S. (2007). "The Role of Multinational Enterprises in Responding to Violent Conflict: A Conceptual Model and Framework for Research", American Business Law Journal 44, 331-358.

Oláh, L.S. and Gähler, M. (2014). Gender equality perceptions, division of paid and unpaid work, and partnership dissolution in Sweden. Social Forces 93(2): 571-594. doi:10.1093/sf/sou066.

Olson, D.H. (1986) Circumplex model VII: validation studies and FACES III. Family Process. 25, 337-351.

Olson, D. H., Gorall D. M., Tiesel J. W. (2007). FACES IV Manual. Minneapolis, MN: Life Innovations.

Olson, D.H. (1999) Circumplex Model of Marital and Family Systems. Journal of Family Therapy, 22, 144-167.

Olson, D. H. (2011). "FACES IV and the circumplex model: Validation study". Journal of Marital and Family Therapy, 7(1), 64-80.

Root, P.P.M. (2001). Love's evolution. Philadelphia: Temple University Press.

Spickard, P.R. (1989). Mixed blood: intermarriage and ethnic identity in twentieth-century America. Madison, WI: The University of Wisconsin Press.

Jo-Pei, T., Buharuddin, R., Juhari, R., \& Krauss, S. E. (2008). "Sociodemographic characteristics of intercultural marriage: A study of a multi-ethnic community in Malaysia". European Journal of Social Sciences, 5, 30-44.

Lim J.H., Lee K.R., Oh M.K., Kwak K.W., Yoon B.B. (1990) “A study on reliability and validity of FACES 3". Korean Academy of Family Medicine. 11(10), 8-17.

Scheffe, H. (1959) The Analysis of Variance. New York: John Wiley\&Sons.

Sneider, L. (2013). Looking back into the future. Moscow, Russia: Piter.

Smith, S., Maas, I., \& van Tubergen, F. (2012). Irreconcilable differences? Ethnic intermarriage and divorce in the Netherlands, 1995-2008. Social Science Research, 5(41), 1126-1137. 
Sunar, D. \& Fişek, G.O. (2005). Contemporary Turkish families. In J.L. Roopnarine \& U.P. Gielen (Eds.), Families in Global Perspective (pp. 169-183). Boston, MA: Pearson.

Tabachnick, B. G., \& Fidell, L. S. (2013). Using multivariate statistics. Boston: Pearson

Ting-Toomey, S. \& Oetzel, G.J. (2001). Managing intercultural conflict effectively. Newberry Park, CA: Sage Publishing.

Türkdoğan, T., Duru, E., Balkıs, M. (2018). Turkish Adaptation of the Family Adaptability and Cohesion Scale IV. International Journal of Assessment Tools in Education, 5 (4), 631-644. DOI: 10.21449/ijate.409110.

Turkey in Statistics (2009), Turksh Statistcal Institute. Retrieved from http://istmat.info/files/uploads/47790/turkey_in_statistics_2009.pdf, Accessed November 2021.

TurkStat (2011), Marriage and Divorce Statistics, Ankara, Turkey. Retrieved from https://data.tuik.gov.tr/Bulten/Index?p=Marriage-and-DivorceStatistics-2020-37211\&dil=2, Accessed May 2021.

TurkStat (2020), Marriage and Divorce Statistics, Ankara, Turkey. Retrieved from https://data.tuik.gov.tr/Bulten/Index?p=Marriage-and-DivorceStatistics-2020-37211\&dil=2, Accessed May 2021.

UN (United Nations). 2001. Principles and Recommendations for a Vital Statistics System - Revision 2. United Nations Publication ST/ESA/STAT/SER.M/19/ Rev.2. New York.

Ukrainians in Turkey (2012, August 26). Retrieved from https://turkey.mfa.gov.ua/tr/embassy/570-ukrajinci-u-turechchini, Accessed December 2020.

Ulusararası Stratejik Araştırmalar Kurumu (USAK). 2008. Yerleşik yabanciların Türk toplumuna entegrasyonu (The integration of settled foreigners within Turkish society). Ankara: USAK.

Wei-Jun Jean Yeung \& Zheng Mu (2020). Migration and marriage in Asian contexts. Journal of Ethnic and Migration Studies, 46(14), 28632879. DOI: 10.1080/1369183X.2019.1585005

Zelenskaya, M.S. (2016). Validation of Family Adaptability and Cohesion Scale Version for Adolescents FACES-IV. Higher School of Economics, Moscow, Russia. 
